\title{
Why Throw the Negs Out with the Bathwater? A Study of Students' Attitudes to Digital and Film Photographic Media
}

\author{
lain Macdonald
}

\section{Abstract}

As today's digital applications hold our gaze and become increasingly ubiquitous, it is easy to dismiss the previous technologies and processes that provided yesterday's creative opportunities. Photography has been revolutionised by digital capture and transmission in the past decade. It could be argued that there is a digital orthodoxy in education, which has democratized and engaged increasing numbers of students, and has had a particular influence in A Level Photography. Over the past decade many traditional darkrooms have been replaced by computer suites. My concern is that if secondary schools and colleges with the facilities to teach film are forced to convert to a singular digital mode, we may be throwing the negs out with the bathwater.
This study uses qualitative and quantitative research that I have undertaken at a Further Education college in England. It explores students' attitudes to learning Photography with an artistic curiosity, which includes experiential learners, and those that eschew the digital age who are content with the organic variety of analogue learning that film offers. They make their own case for maintaining the opportunity to learn through hybrid activity that embraces both media, for a multiplicity of learning opportunities and media that are not limited by any orthodoxy, digital or otherwise.

\section{Keywords}

photography, orthodoxy, digital, analogue, pedagogy 
Background to the study

We have a darkroom. It's not been used in years. (Head of Art, Secondary School, extract from interview notes, undertaken by the author in May 2007)

A few years ago, while I was deciding in what direction my career should go, I had a work placement at a local secondary school. The art teacher greeted my photographic experience with enthusiasm - maybe now the darkroom could be recommissioned. My heart sank when I opened the darkroom door to find my way barred by stacks of old GCSE canvases and dusty sculptures. One wonders whether there are many similar pressing uses made of darkrooms across the country. Perhaps it would be better to go digital? It is the future, we are told, and children are already familiar with it (Davies \& Worrall 2003; Prensky 2001).

Since the New Labour government's review of secondary education in 1997 there has been an emphasis on preparing children for a digital future. ICT (Information and Communication Technologies) has a mandatory place in the National Curriculum, and in Art and Design there has been a lively discourse in how digital technologies can be embraced and why. Within the art education establishment Allen (2003), Ash (2004), Davies \& Worrall (2003), Long (2001), Meecham (2000) and Newbury (2004) all promote the opportunity for ICT to engage and further learning in art. It could be argued that progress has been made in the space of 10 years between Watson's (2001) concerns at the lack of progress and the pedagogic anxiety with ICT, and the 2009 OFSTED report on art education in England and Wales which found that digital media was at last making a positive impact on pupils' attainment and the exploration of abstract concepts: 'It was most effective in schools where digital cameras were freely available, professional software was used, and computers and the internet were adjacent or integral to studios' (OFSTED 2009, 18)

Boys particularly improved in art classes when ICT was provided. However, this report was balanced by the finding that the impact was still surprisingly slow considering the rapid digital development in the creative industries and contemporary culture, which has been echoed previously (Downing \& Watson 2004; Long 2001; Wood 2004).

Addison et al. $(2010,29)$ conclude that now 'there is real momentum' to use digital media in the art classroom and I believe the argument that there is a digital orthodoxy in education is compelling. By this I mean that the established opinion in politics and education regards digital as the dominant media, over and above traditional analogue modes. Addison etal. $(2010,46)$ also acknowledge that the 'visual landscape of global communications' is dominated by digital media. Davies \& Worrall $(2003,91)$ refer to an 'emerging ICT orthodoxy ... in our schools'. Students who struggle with traditional media are finding recognition as competent manipulators of digital media (Wood 2004), which 'is often supported by considerable home use' (Davies \& Worrall 2003, 92). Born into a digital world, pupils are 'digital natives' and often they are informing the teachers, the 'digital immigrants' (Prensky, in Stead 2006). This digital revolution is also enabling children to be producers - online artists, bloggers - where text and image are transmitted globally. This could be compared to Benjamin's observation in 1936 of the extension of the newspaper press in the twentieth century which gave authorship to readers who found they were able to contribute as writers in letters to the editor and contribute articles to countless magazines: 'literary licence is now founded on polytechnic rather than specialised training and thus becomes common property' (Benjamin 1992, 225).

Digital photography has opened up enormous opportunities in art and design education but also across other subject areas. Digital media has brought urgency to media literacy but has also enabled it (Buckingham \& Sefton Green 1994). On the Flickr website alone there were 4 billion digital images online in October 2009 (Flickr 2009). Nearly 20 years previously, predigital photography, Bourdieu (1990, 47) suggested photography is for everyone, it is 'the most ordinary thing of all' and its use 'is not the 
product of training or education'. This is even more valid today with the availability of inexpensive digital cameras and mobile phones with built-in cameras.

There have been many articles published in the International Journal of Art and Design Education (iJADE) which focus on the positive impact of ICT in art and design education, but these are largely 'descriptive and anecdotal' and there is a need for 'more critical research and evaluation to inform educators how the dynamics of educational interactions may change when mediated by technology' (RadclyffeThomas 2008, 165). 'Technology can also be used to question what we value and why' (Meecham 2000, 225). It can be used to gain an understanding of how we understand our relationship with technology (Freedman 2003; Meecham 2000). This study aims critically to analyse the pedagogies of digital and film photography using quantitative and qualitative methodologies at an English Further Education college.

For over 20 years I have worked as a graphic designer and director in television and advertising, embracing new technology to create images. But recently, as an MA student and teacher of photography at A Level, I have had the opportunity to glance back over my shoulder to evaluate what might be at risk of being left behind and forgotten, the heritage of analogue, the art of film photography. I would argue that film is a heritage medium, because the chemical process is the original invention and the present and future are digital. By following a digital orthodoxy in photography education is there a risk of throwing the negs out with the bathwater?

The problem of the study: which tools for the job?

The study sought to discover if A Level Photography students had a preference for a particular medium and if their choice of tools affected the outcome of their learning. 'What the film in your camera can do influences what you will do' (Eisner 2002, 8). If you have a black and white film in your camera you will compose your shot using shadows, but if you have colour film you will be more sensitive to the colour in the frame. Eisner $(2002,23)$ uses this example to argue that the choice of medium of representation dictates the content and how it is represented: 'Thus, representation influences not only what we intend to express, but also what we are able to see in the first place.' So according to Eisner the choice of tools may depend on the intended task.

Yet Raymond Williams (1981) has argued that there is nothing in a technology itself, such as mechanical or digital photography, which determines its usage in a culture or society. New technologies are constantly being invented, especially in photography, and they become incorporated within 'established relations' in the mainstream activity, 'contributing to articulating - but not causing - shifts and changes in such relations and patterns of behaviour' (Wells $2004,13)$. Newbury considers there to be positive opportunities with technological developments that are not predetermined but offer 'new kinds of photographic and cultural practice, and a rethinking of what it means to teach such subjects' (Newbury 1997, 434). Addison (Addison \& Burgess etal. 2010, 46) warns that education must be 'wary of technological determinism' and that learners in all artistic practices can use their bodies as tools or 'in conjunction' with materials as a 'fundamental and potentially inexhaustible technological resource'. Wood (2004, 187 ) is wary of technology's trickery that can distract students from developing their ideas, but while art and design and photography teachers are as excited by digital tools as their students are they losing touch with the 'real thing'? Baudrillard asks is anything real any more, and the debate over the honesty and integrity of the image in the era of post-photography is hotly debated (Baudrillard 2009; Ritchin 2009; Wells 2004).

\section{Theoretical framework}

As we have seen, Benjamin (1992) and Williams (1981) can offer a position of theoretical reference in the debate surrounding the effect of the development of technology. Benjamin not only
193

lain Macdonald 
provides a possible comparison to the democratisation of online digital publishing but also the loss of 'aura' of the mechanically reproduced image. Do the students value a digital image any less than a chemically produced film print? How might that change the value of their learning experience?

Williams (1981) describes some of the different motivators that determine the choice of technology and how different groups are created. They may be created by different economies or ability to access technology or a variance in expertise and knowledge. Do film or digital photographers see themselves as a distinct social group in the cohort? Williams $(1981,70)$ might classify this type of cultural relationship as being a 'specialising' group, one that sustains or promotes work in a particular medium and which fits easily into an 'open or plural society'. There may be other colleges where film photography is more alternative or even in oppositional conflict with the digital orthodoxy and Williams $(1981,70)$ points out historical examples such as the Dadaists, where culture and art have seen 'significant local conflict'.

We are going through what Williams would call a 'transitional period', where forms of production and reproductions overlap. Our focus should be on the 'innovations' not just the 'characteristics' of the work because 'this is one of the very few elements of cultural production to which the stock adjective, "creative", is wholly appropriate' (Williams 1981, 200). How does that sit with the digital orthodoxy?

Perhaps the most recent significant overlapping form of production came with the invention of Photoshop in 1990 (Adobe 2010). In that time it has developed and transformed image manipulation in domestic and industrial practices. Any digital image can be manipulated in Photoshop, even analogue film negatives and prints that are digitally scanned. It is used for the postproduction of digital photographs: cropping, colour correction, super-imposition, montaging to name but a few. Photoshop's use in education is by no means universal, but in all my secondary school placements there was at least one computer with Photoshop in the art room, which was used to teach pupils as young as 12 .

\section{Methodology}

The focus of my study was the A Level Photography students at a Further Education college where I taught photography between September 2009 and April 2010. Bell (1999) and Cohen et al. (2007) suggest a questionnaire as an important data gathering tool to help to focus deeper research questions. Cohen et al. (2007, 351) also highlights an advantage of a questionnaire: 'that it tends to be more reliable because it is anonymous, it encourages greater honesty'. I constructed a questionnaire to identify any trends that might suggest a preference of media or technology between gender, AS and $\mathrm{A} 2$, the ownership of cameras and any other influencing factors that might determine their preferences. A set of 21 questions were answered using the Likert scale to gauge the strength of opinion for or against (see Table 3). The opening question was designed to identify the greater use of either a digital or film camera. The following four questions then sought to establish if there had been a difference in opportunity or teacher influence in the choice of media. The remaining questions looked for any other influences in learning approaches and the classroom environment. Students were also asked to write a brief explanation for why they might or might not have a particular preference for digital or film media as photographers. Out of a possible 200 recipients, 166 returned completed questionnaires. If there were any distinct preferences for a digital or analogue tool it was then necessary to find out what those people might be like and what their reasons were for making that choice. Was there a difference in the approach to their learning?

I invited nine students to be interviewed on video and photographed for further qualitative research. These students were initially selfselecting from each class. They answered a list of structured questions that were essentially heuristic, designed to illuminate the student's way of learning. This was a more ethnographic approach than the questionnaire, as it required 


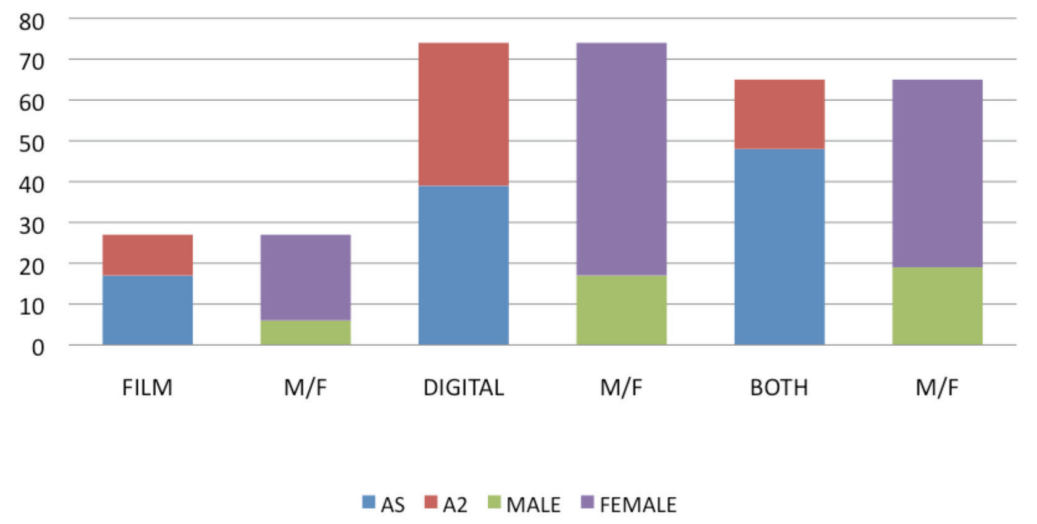

the students to explain in their own words their feelings and experiences in order to try to make sense of how they learn photography. Within the study it was important to establish whether the students felt free to choose their own preferred media, and to be conscious of any potential bias in the video analysis that might arise from my presence as both lecturer and researcher sitting behind the camera (Hickman 2009).

Hickman labels this use of both quantitative and qualitative approaches as 'hybrid' and sees it as 'compelling', but he quotes Bamford to assert that 'research within art education is more comfortably located within the naturalistic paradigm' where the 'multiple constructions of reality' can be accommodated and interpreted visually (Hickman 2009, 17). Using my own practice as a photographer and digital artist, I designed an exhibition, which was in part reflexive, that presented the edited interviews and the students' work within an interactive screen display alongside film and digital portraits of the interviewees. I shot the film portraits as neutrally as possible and exhibited them with their mobile phone self-portraits. Their self-expression was contrasted with my detachment. The audience could explore the evidence in either a conventional gallery experience or a more interactive digital one.
The results

\section{Agency}

It was important at the outset to establish whether the students had agency in their choice of either film or digital media: $57 \%$ of students had a neutral response to the question of whether teachers have had an influence on their choice of media; $90 \%$ believed that they have been taught both digital and film to an equal degree (see Table 2).

\section{Film, digital or both?}

The survey of A Level photography students at this college showed that there was a significant body that liked both media, 39\% (see Table 1). Those that preferred film only made up $16 \%$ of the sample, while $45 \%$ preferred digital. If we were to combine the results of those with equal preference with those that preferred film it would suggest that a majority of students enjoy working with film. Has digital photography yet to completely supersede film in an educational context?

\section{Camera ownership}

Some $74 \%$ of students owned both film and digital cameras irrespective of a digital or film preference (see Table 3). There seems little evidence of any economic influence in their choice of media, despite the contradiction that many remark on the expensive cost of film and photographic paper but those who prefer digital have the highest ownership of both film and digi- 
196

lain Macdonald

Table 2: Testing the college provision of both digital and film media
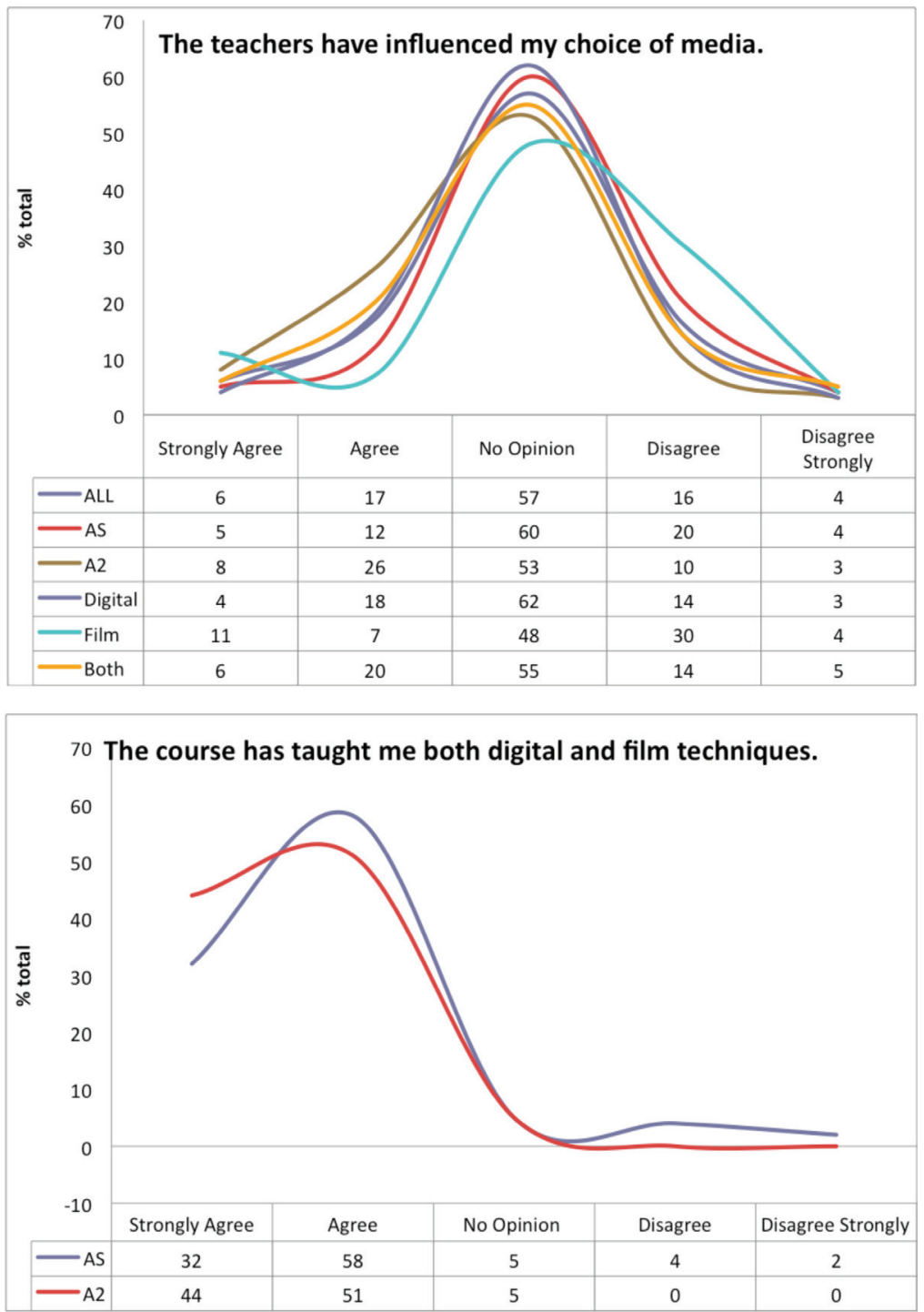

tal cameras. The college has a duty of inclusion and so there is a limited provision of photographic equipment (good Nikon DSLRs and Pentax SLRs) available to all students irrespective of economic status. The proportion of students claiming EMA (Education Maintenance Allowance) enrolled on A Level Photography is similar to that of the college as a whole and so this indicates that there is no obvious economic impediment to students wishing to study photography.

\section{Does purpose affect the choice of camera?}

Students are more likely to use a digital camera to take their first photo than a film camera. It is more likely now that it will be a mobile phone rather than a pocket digital camera. It is handy and in their pocket ready for when inspiration strikes. Even the students that prefer film cameras can see the value of shooting digitally:

I think a digital camera is not essential but it helps, you can just take quick snap shots and 
Table 2 (continued): Testing the college provision of both digital and film media

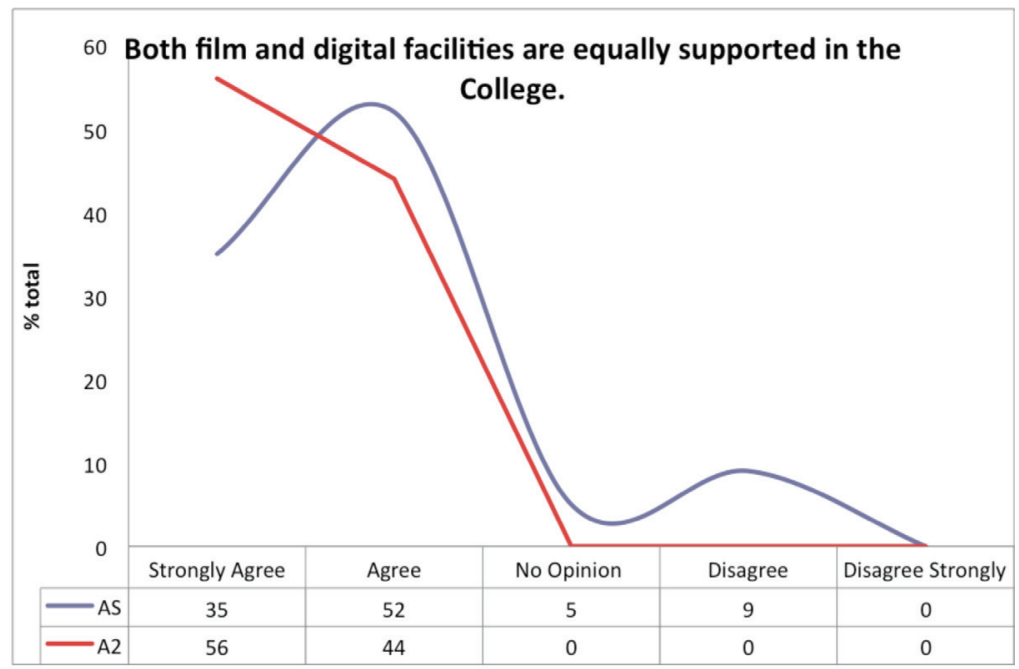

then from there / find I can focus my ideas more. (Male AS Pref Film)

Digital cameras are used by all the students for creative experimentation or for just capturing an idea that can be worked on later. For these digital natives it is an instinctive response. Over $83 \%$ of students recognised a different aesthetic quality between film and digital (see Table 9), so the choice a student makes between film or digital photography is significant and is a conscious decision (see Figure 1). While they may value the scarceness of film and its aesthetic difference, this finding does not yet indicate if they appreciate a greater 'aura' in film. One student certainly felt they had to invest more of themselves in each film image because of the limited number of shots in a roll of film:

But I feel using film is much more emotive because you have to think a lot more about what you want to take a photo of, because obviously you have to pay for film and you only have 24 shots. Whereas with digital you can be quite snap-happy and just go overboard with taking hundreds of pictures, whereas with film it's much more you have to capture the right image at the right time so that you don't waste it really. (Female A2 Pref Film)

\section{AS and A2}

There are bigger differences in the split of AS and $A 2$ students across the groups (see Table 1). Looking at the distribution of students, it suggests that there is proportionally more film usage at AS level than at A2. One A2 student explained why this might be the case:

Second year is quite rushed and it's so much more work. I'd rather just getall the images right and get them in there. (Female A2 No Pref)

There is evidently an expedience to digital cameras irrespective of any aesthetic differences that might appeal in second year of $A$ Level.

\section{Does the use of computers have an influence on media preference?}

Digital photography is taught using the computer based image-editing programme Adobe Photoshop. Some of the film photographers found Photoshop 'confusing' and one was 'scared' of it. Students with a film preference showed a remarkably negative response to the statement 'Photoshop suits me because I can produce quick results', whereas the rest were positive (see Table 5).

The students who were interviewed also 
198

lain Macdonald

Table 3: Questionnaire responses

\section{PHOTOGRAPHY QUESTIONNAIRE RESPONSE TOTALS}

$\begin{array}{llll}\text { Gender } & \text { MALE (42) } 25 \% & \text { FEMALE (124) } 75 \% \\ \text { Level } & \text { AS (104) } 63 \% & \text { A2 (62) } 37 \% & \\ \text { Own Camera } & \text { DIGITAL (6) } 4 \% & \text { FILM (36) } 22 \% & \text { BOTH (121) } 74 \% \\ \text { Preferred Media } & \text { FILM (27) } 16 \% & \text { DIGITAL (74) } 45 \% & \text { BOTH (65) } 39 \%\end{array}$

\begin{tabular}{|c|c|c|c|c|c|}
\hline & $\begin{array}{c}\text { strongly } \\
\text { agree }\end{array}$ & agree & $\begin{array}{c}\text { no } \\
\text { opinion }\end{array}$ & disagree & $\begin{array}{l}\text { strongly } \\
\text { disagree }\end{array}$ \\
\hline $\begin{array}{l}\text { 1. I use a digital camera as much as a film } \\
\text { camera. }\end{array}$ & 23 & 38 & 13 & 68 & 23 \\
\hline $\begin{array}{l}\text { 2. The course has taught me both digital and film } \\
\text { techniques. }\end{array}$ & 60 & 91 & 8 & 4 & 2 \\
\hline $\begin{array}{l}\text { 3. Both film and digital facilities are equally } \\
\text { supported in the College. }\end{array}$ & 71 & 81 & 5 & 9 & 0 \\
\hline $\begin{array}{l}\text { 4. The teachers have influenced my choice of } \\
\text { media. }\end{array}$ & 10 & 28 & 95 & 27 & 6 \\
\hline $\begin{array}{l}\text { 5. The cost of photography has influenced my } \\
\text { choice of media. }\end{array}$ & 30 & 57 & 30 & 33 & 15 \\
\hline $\begin{array}{l}\text { 6. Digital cameras are simpler to use than film } \\
\text { cameras. }\end{array}$ & 29 & 53 & 40 & 33 & 10 \\
\hline $\begin{array}{l}\text { 7. I get confused by all the different settings } \\
\text { available on digital cameras. }\end{array}$ & 12 & 44 & 36 & 54 & 19 \\
\hline $\begin{array}{l}\text { 8. Photoshop suits me because I can produce } \\
\text { quick results. }\end{array}$ & 20 & 51 & 37 & 39 & 17 \\
\hline $\begin{array}{l}\text { 9. The darkroom gives me time to think and } \\
\text { come up with ideas. }\end{array}$ & 8 & 56 & 62 & 32 & 8 \\
\hline $\begin{array}{l}\text { 10. It is easier to experiment with different } \\
\text { materials in the darkroom. }\end{array}$ & 18 & 63 & 45 & 37 & 3 \\
\hline $\begin{array}{l}\text { 11. Digital cameras give me confidence because I } \\
\text { can see an instant result. }\end{array}$ & 56 & 75 & 21 & 11 & 1 \\
\hline $\begin{array}{l}\text { 12. Working with film gives me greater control } \\
\text { because I can see and feel what I am doing. }\end{array}$ & 13 & 32 & 52 & 58 & 10 \\
\hline $\begin{array}{l}\text { 13. I spend my free time playing computer games } \\
\text { and/or creating my own artwork on my } \\
\text { computer. }\end{array}$ & 8 & 30 & 37 & 56 & 34 \\
\hline $\begin{array}{l}\text { 14. I think computers are everywhere; it's good to } \\
\text { be able to use traditional methods with film. }\end{array}$ & 20 & 76 & 49 & 18 & 2 \\
\hline $\begin{array}{l}\text { 15. I prefer digital photography because it's } \\
\text { cleaner and not as messy or smelly as film. }\end{array}$ & 17 & 48 & 42 & 39 & 19 \\
\hline $\begin{array}{l}\text { 16. I like to see how chemicals react with the } \\
\text { photographic paper and to see the image } \\
\text { develop. }\end{array}$ & 25 & 87 & 42 & 7 & 5 \\
\hline $\begin{array}{l}\text { 17. The darkroom is claustrophobic and makes } \\
\text { me anxious. }\end{array}$ & 8 & 23 & 24 & 56 & 55 \\
\hline 18. The computer room gives me a headache. & 4 & 30 & 40 & 50 & 41 \\
\hline $\begin{array}{l}\text { 19. You can't see the difference between a film } \\
\text { and a digital image. }\end{array}$ & 2 & 8 & 18 & 53 & 83 \\
\hline $\begin{array}{l}\text { 20. My digital images look better than my film } \\
\text { images. }\end{array}$ & 25 & 38 & 58 & 33 & 11 \\
\hline $\begin{array}{l}\text { 21. At home I use digital but for college I use a } \\
\text { film camera. }\end{array}$ & 10 & 23 & 58 & 55 & 19 \\
\hline
\end{tabular}




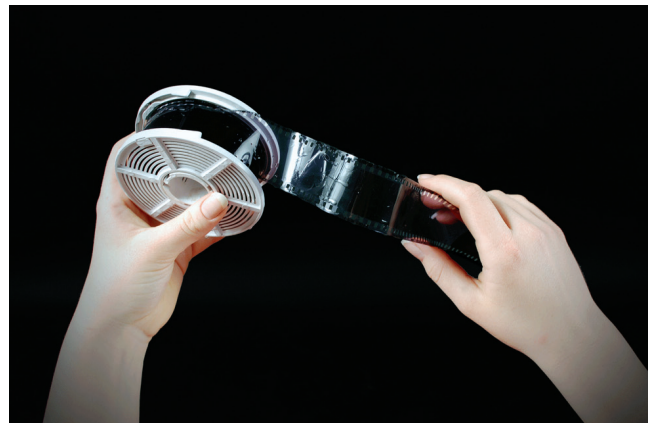

feared losing their work or having their memories being wiped by a computer. For one film photographer his mistrust of digital archiving could only be assuaged by a tangible, physical print or negative to hold memories and creative work. To him a film negative felt more real than a digital photograph on a computer:

With a lot of digital it just ends up getting lost on the computer... and not stored on a solid form. (Male AS Pref Film)

Yet, for many, film is a more risky medium and mistakes can lead to a significant loss of confidence and a stifling of any learning progress:

Sometimes I've taken an amazing film and nothing has come out in the darkroom, and that's definitely a negative aspect. (Female A2 No Pref)

The popularity of digital is clearly linked to the reassurance that comes with an instant playback: $80 \%$ of students agreed that digital cameras give them confidence because they can see an instant result (see Table 5). For others, compared to film, it is the familiarity of digital cameras that makes them easier to use:

Learning film you have to go right back to the basics where you are just completely going into the unknown. With digital you've obviously got the little digital cameras that you use all the time so you know roughly what you're doing ... (Female 2 AS No Pref)

Yet, surprisingly for these young people, there are other methods in photography that are just

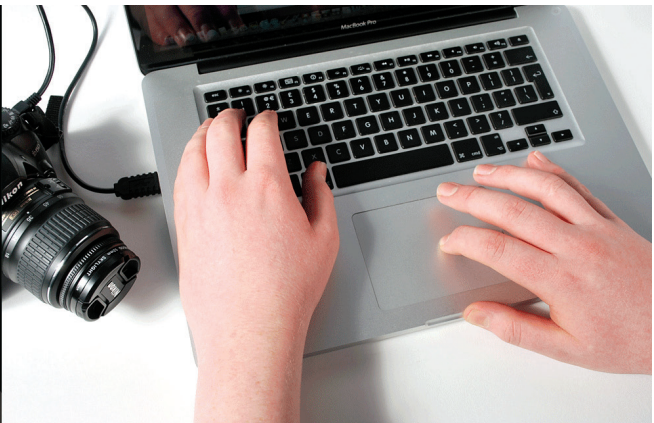

199

lain Macdonald

as satisfying as the instant gratification of digital media. Looking at pedagogic practice, some students appreciate the value of learning the concepts of photography through film before moving on to perhaps more complex digital options:

But I think if you do photography you always have to do film first and then you go on to digital. (Female AS Pref Film)

\section{Environment: lost in time}

For my first time going into the darkroom it was like a whole new environment but because I enjoyed it so much I just wanted to learn loads, and like this is so exciting, and opening and closing the aperture on the enlarger, and different effects you get from different filters and all that kind of stuff. It was do-able, I could, I just walked in and just followed the instructions, did some experimentation. So if / exposed the photo for two seconds I went and tried three and five seconds to see what the differences would be. (Male AS Pref Digital)

For many students the darkroom is seen as a central aspect of photographic practice. This is what photography is all about:

That was one of the reasons / came, because of the darkroom ... Isaw the darkroom and I thought yeh, I wouldn't mind doing that... (Male AS Pref Film)

However, some students find the darkness of the red light and the atmosphere with the chemicals difficult to work with:
This page:

Figure 1

Analogue film and digital photography 
200

lain Macdonald

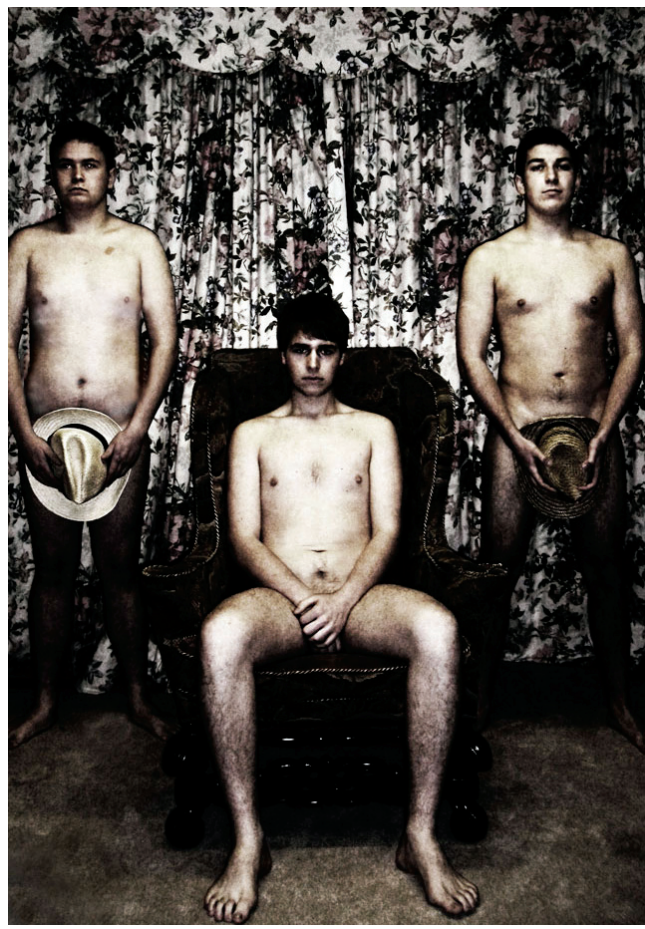

I've never been able to put the film on the coil because it's so dark in the darkroom (laughs). (Female AS Pref Digital)

This undoubtedly creates some stress, which is amplified if films fail to come out.

In an extreme case one female student passed out after feeling claustrophobic and disorientated. For reasons of safety a teacher is always present or in the vicinity of the darkroom. In a mixed college with teenagers that also takes on a special importance in order to protect students' right to their personal space without fear of any kind of physical interference. Some may regard the darkroom as an extension of their bedroom, and while this is strictly forbidden there are legends and rumour that add a frisson to the space. Added to this are the plentiful images of semi-nude teenagers that they have photographed in order to explore and validate their own physical appearance and sexual identities (see Figure 2). This is hardly surprising when they are bombarded by advertising images that sexualise teenagers (Giroux 2009).

For others the darkroom is a refuge, a place where they can put the radio on and cut themselves off from the stresses of college while working away 'in the zone', that place where the creative mind loses all concept of time. They are 'more involved' in their work. This is ironic considering watching the clock or the timer is the main activity in the darkroom. Perhaps it also offers a 'space in an education programme that is otherwise mostly theoretical' (Erixon 2010, 1215)? As a practical art it has an air of the 'exotic' in a digital orthodoxy (Erixon 2010, 1215). This is supported by the survey which showed that students, and particularly film photographers, thought that it was good to use traditional methods as a change from computers (see Table 4). In a digital orthodoxy there may be an advantage in maintaining a heritage medium to provide a balance to the curriculum.

Within the first week of learning, photography photograms are introduced to immediately challenge students' concepts of photography. Some are surprised at the many opportunities to assemble and create objects and textures that can interrupt and distort the projection of light on to the paper-impossible with digital technology. For some it is a process they return to later in the course when they have more sophisticated darkroom and digital skills.

But the darkroom also offers a very compelling learning experience for students to learn the basic principles of photography that can then be transferred on to digital processing on the computer. That takes place in a very different environment, in a room that looks more like an IT suite than a photography lab. Some $50 \%$ of students found the darkroom 'simpler' than digital processing (only $24 \%$ disagreed) (see Table 5). It provided a foundation of basic photographic principles that they could use to understand the various functions displayed on Photoshop, such as dodging and burning, exposure and contrast controls. These students valued learning through the knowledge transfer between analogue film and digital photography:

I think by doing it in the darkroom you see the simple way of doing things and somehow it's simplerwhen you go to Photoshop, because you 
Table 4: I think computers are everywhere, it's good to be able to use

201

traditional methods with film

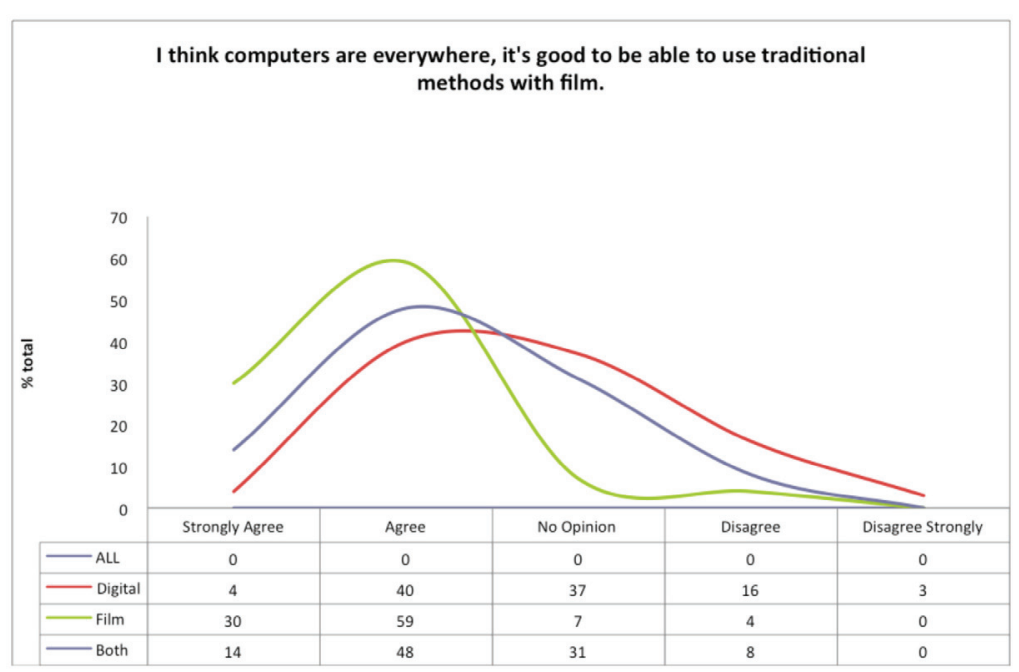

Table 5: Testing views and use of digital cameras

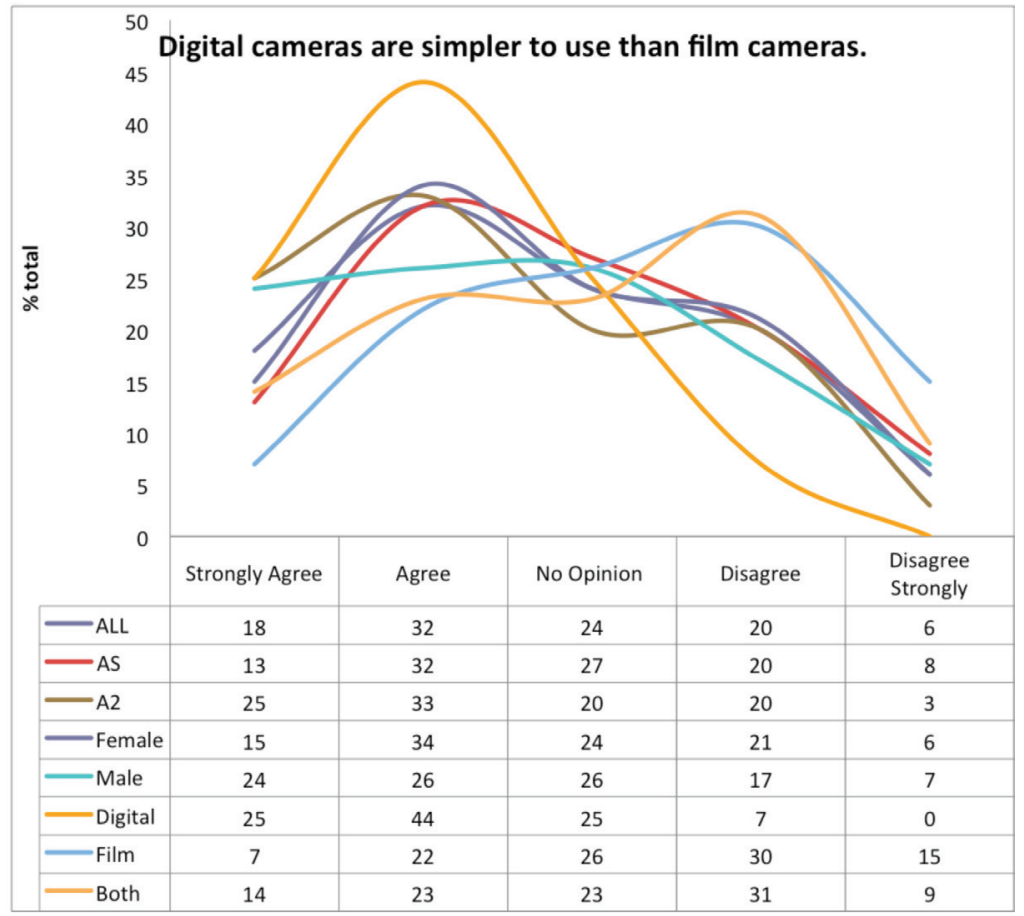

Opposite page:

Figure 2

AS student (female) digital photograph 
202

lain Macdonald

Table 5 (continued): Testing views and use of digital cameras
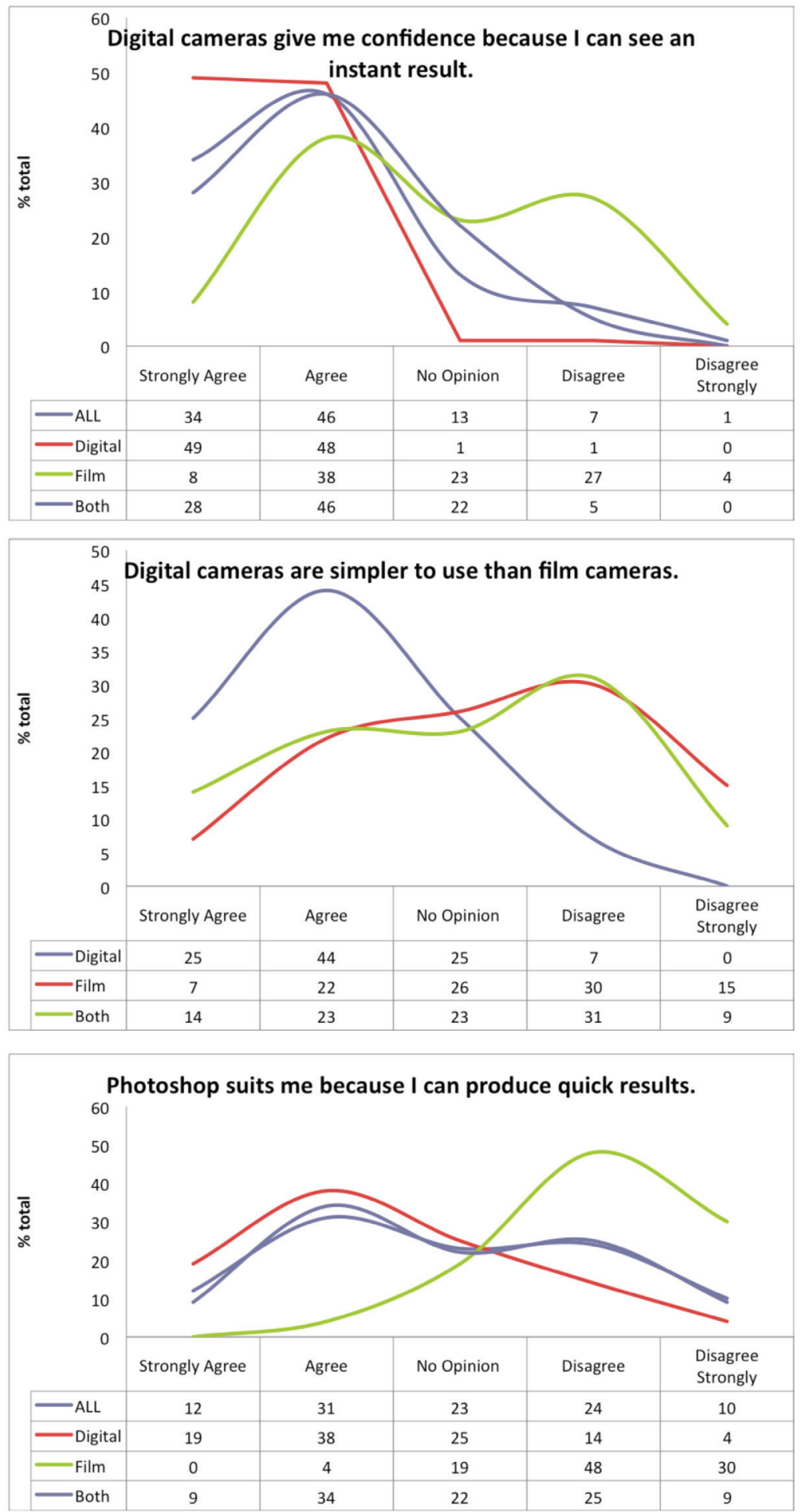
can see how it's done. Before when I didn't know how to do things in the darkroom it was like everything was really complicated to understand how it worked. So it makes it easier to understand the basics. (Female AS Pref Film)

You can transfer what you know from film to the digital. (Female AS Pref Digital)

... anything you can do in the darkroom you can do in Photoshop, so that was quite cool. (Male AS Pref Digital)

One student declared 'computers can do anything' even make digital pictures look 'like an old film photo they'd think it was just done in Photoshop ...' (see Figure 3). Perhaps this suggests that a film photograph is just as likely to be read as a fake as a real image?

Photoshop is a 'heuristic tool for understanding and rehearsing photographic codes and qualities' (Wells 2004, 316). It is contributing to our understanding of the language of photography, but the preparation for that begins in the darkroom. While for these students there is a 'magic' in the alchemy of the darkroom, for Ritchin $(2009,30)$ 'in the nascent digital era, the photograph was already extant and the magic was in modifying it'.

\section{Interpretation: specialising groups and their pedagogies}

It is argued that students learn in different ways: there are auditory, visual, kinaesthetic or tactile learners (Addison \& Burgess 2000; Gardner 1996; Hardcastle 2004). Some students are very aware of their learning preferences, they have self-efficacy (Addison \& Burgess et al. 2010):

I find when I learn I have to be actually doing it... otherwise it doesn'tseem to go in. I have to do it to remember it. (Male AS Pref Film)

It was interesting to see if there was any correlation with these and their preferred media. 'A person's innate talents predispose the person to seek certain kinds of experiences in the envi-

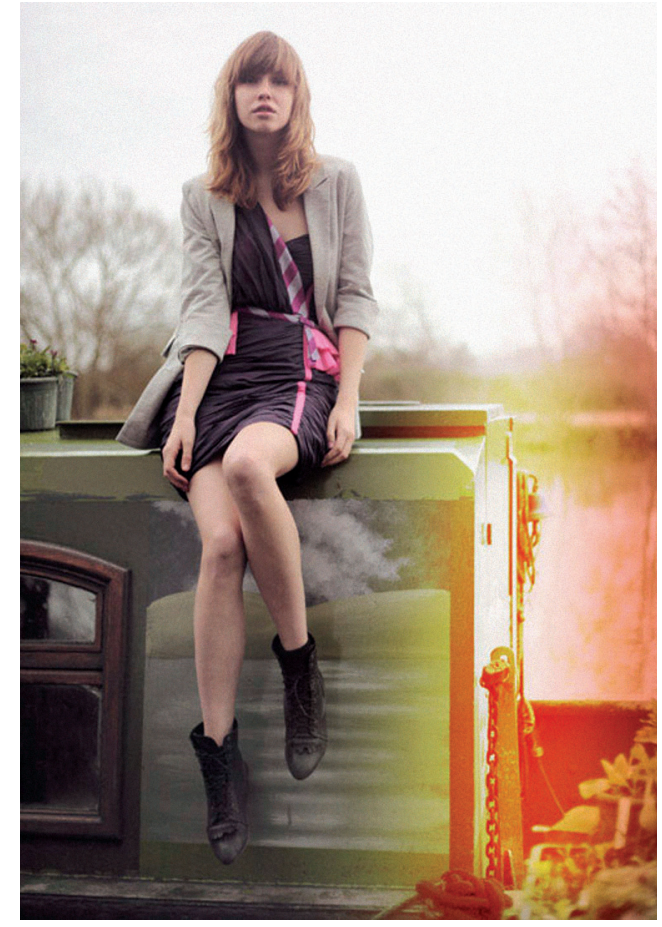

203

lain Macdonald

ronment' (Mayer 2003, 268). Within a learning environment that supports and provides a plurality of photographic technologies and media, different 'specialising groups' are able to exist, which follows Williams' (1981) theory previously discussed. How did their learning approaches differ?

All students showed an independent approach to learning digital processes, whereas some digital photographers tended to 'need one-to-one teaching for film' (see Figure 4). With film students they learn from demonstrations, mimicking the techniques and procedures shown by teachers as well as other more able students and friends (Eisner 2002). They need to be able to learn through practical application and experimentation in a learning environment that allows for mistakes. This develops tacit knowledge, which requires 'imitation, practice, repetition and complete immersion: it takes time, what Polanyi calls "indwelling"' (in Addison \& Burgess 2000, 36). With regular access and practice they develop their skills and techniques to tailor working routines to suit their individual learning styles; they have
This page:

Figure 3 AS student digital photograph synthesising an analogue film fogging 


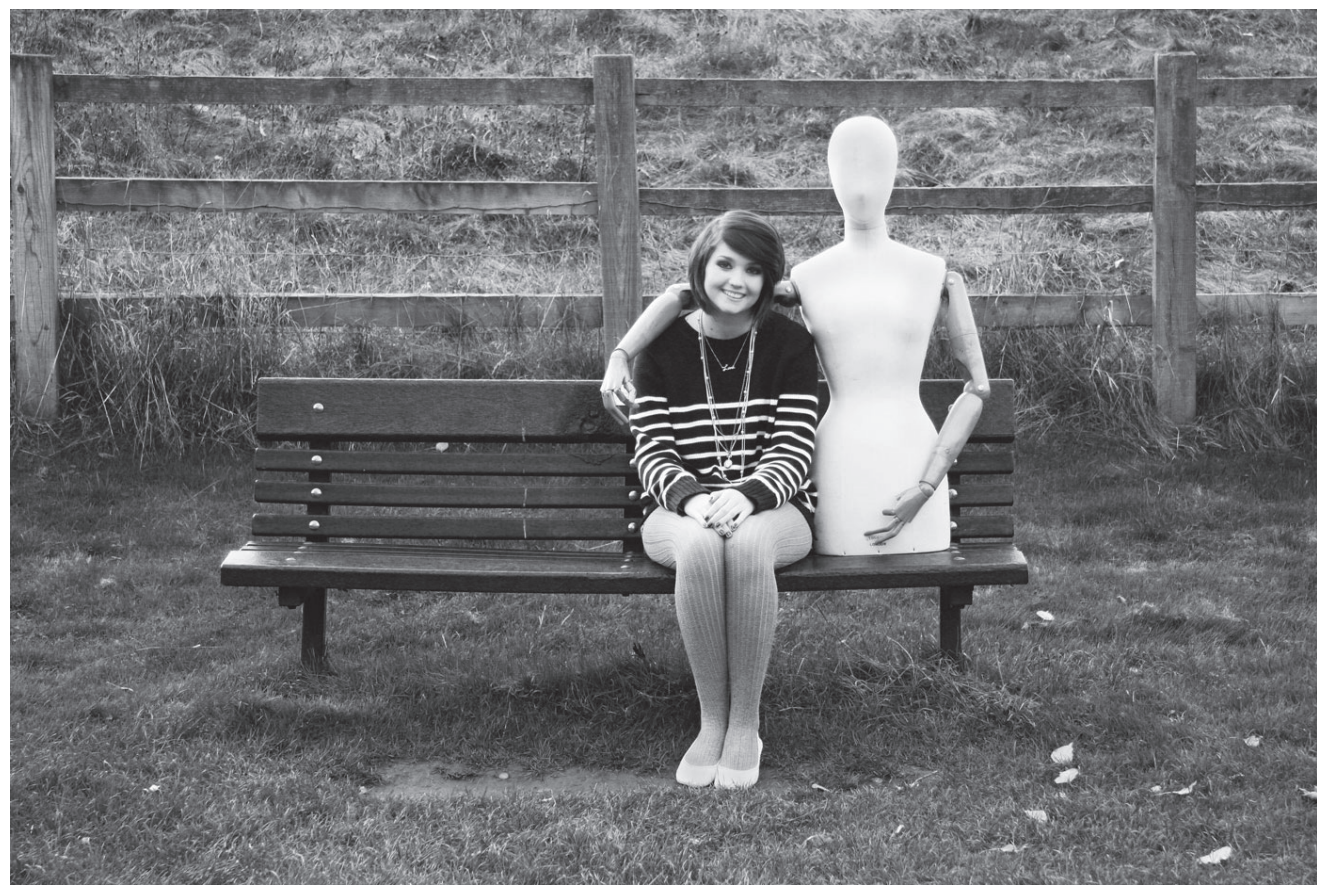

agency (Addison \& Burgess et al. 2010). Students become familiar with the 'domain of knowledge' and find 'short cuts' through an 'implicit perception of the total problem' (Addison \& Burgess 2000, 39). One student investigated a process called 'liquid light', a lightsensitive chemical that can be applied to surfaces:

I wanted to have a go myself and experiment with it, try different things. I've just been looking at the internetfor tips and techniques. Then I had a go and it just went completely wrong, and I think the way to learn is just to get it wrong and know what not to do in order to get it right next time. And that's helped me a lot. (Female A2 Pref Film)

In common with the other students, the 'transitional' group (Williams 1981), those that liked both film and digital, also learned by 'doing', 'kinetically' as one student described her learning preference. 'Practice, practice' and 'learning from mistakes' through 'experimentation' were common remarks. There was, again, a common independent approach to learning using online resources, but with recognition of the importance of teacher demonstration in class. One student used her 'photographic memory' to learn from the demonstrations and screen presentations. However, like those with a film preference, none of these students felt they could learn from reading instruction sheets, which was seen as an unsuitable way to learn photographic techniques and skills:

I could never sit down and just read an instruction book, I have to just go outand do it and that's the best way to learn it really. (Female 1 AS No Pref)

Yet some students with a preference for digital photography would read an instruction manual, even though they considered it 'easier' to learn because they could see instantly whether the photograph had 'come out' successfully (see Figure 5) (see Table 5):

Basically / try everything out, press all the buttons, see if they work, see how they work and then read the booklet if I don't understand them. (Female AS Pref Digital) 
Table 6: Do digital images look better than film images?

205

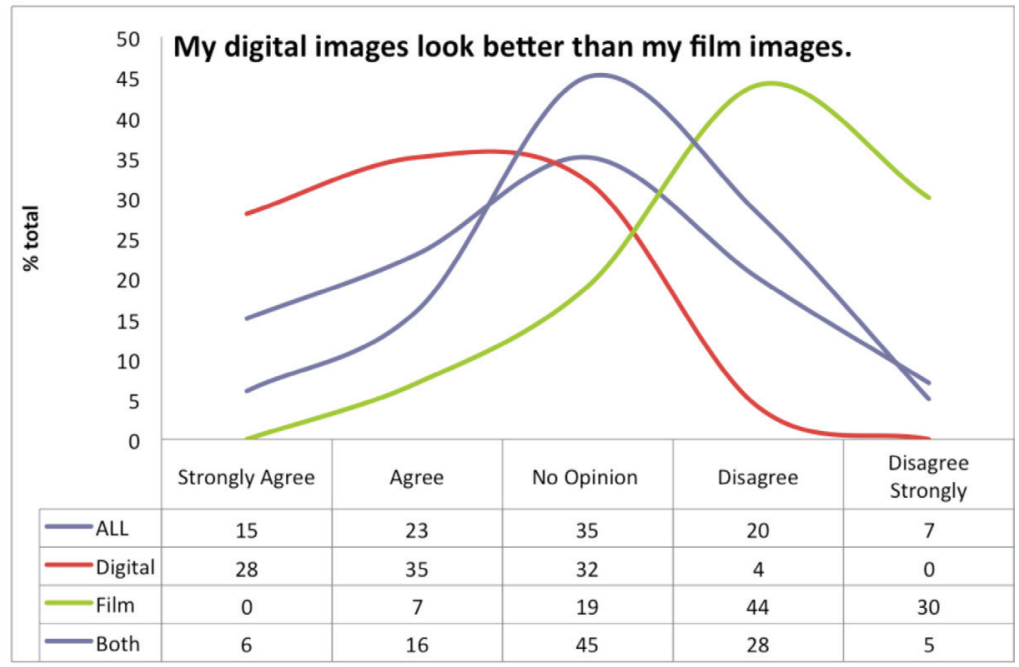

lain Macdonald

Table 7 : Do students enjoy seeing the chemical process of images appearing on photographic paper?

\begin{tabular}{|c|c|c|c|c|c|}
\hline \multicolumn{6}{|c|}{$\begin{array}{l}\text { I like to see how chemicals react with the photographic } \\
\text { paper and to see the image develop. }\end{array}$} \\
\hline \multirow[t]{2}{*}{ 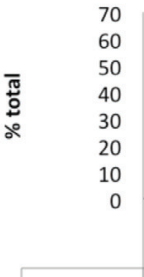 } & & & & & \\
\hline & Strongly Agree & Agree & No Opinion & Disagree & $\begin{array}{l}\text { Disagree } \\
\text { Strongly }\end{array}$ \\
\hline$\longrightarrow \mathrm{ALL}$ & 15 & 52 & 25 & 4 & 3 \\
\hline —Digital & 8 & 47 & 34 & 7 & 4 \\
\hline Film & 33 & 52 & 7 & 4 & 0 \\
\hline Both & 15 & 58 & 20 & 3 & 3 \\
\hline
\end{tabular}

They were able to make instant changes, to experiment with confidence in the knowledge that they were getting results. Added to 'quicker results', they also found that 'quality' improved without the scratches and water marks which occurred on their film negatives (see Table 6). Digital photography was regarded as being 'easier' to learn because it is also part of their out-of-school experience. Most of the students interviewed found digital software like Photoshop 'easy to pick up', mostly through 'play' and were helped by online tutorials on You Tube, for example. Born after the launch of Photoshop, they have grown up as 'digital natives'. In Sweden Erixon (2010) found that relations between teachers and students were changing as the 'digital natives' (Prensky 2001) were helping the digital immigrants. Teachers are having 'to do away with their prestige ... [and] as a consequence of this, the classroom relations are becoming more intimate and hence more positive. The pupils learn more' (Erixon 2010,
Opposite page: Figure 4 AS student film photograph 
206

lain Macdonald

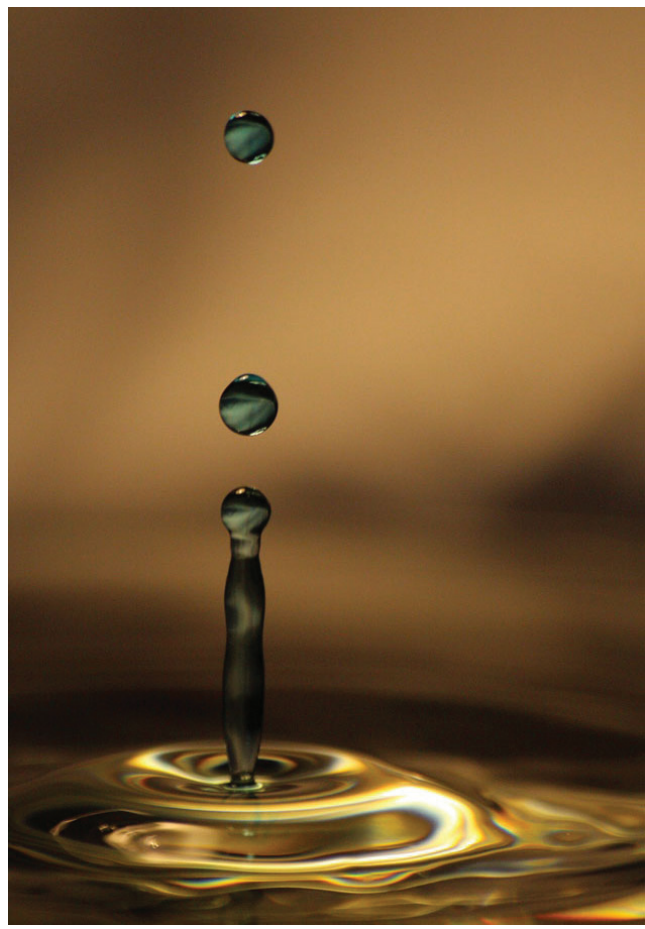

1218). It is possible that unless teachers allow themselves to be open to learning from their students they could become an 'oppositional group', as described by Williams (1981). If teachers are closed to new technology and resist adapting their practice to meet the demands and contemporary practice of students, then they will surely find themselves in a culture that is irrelevant.

The 'traditional' skills are learnt through demonstration and practice by doing, as Dewey would suggest (Addison \& Burgess 2000). The manipulation of 3D media requires similar motor control and dexterity to that a student might expect to learn in other handicrafts. Ash (in Addison \& Burgess 2000, 212) argues that in $2 \mathrm{D}$ only 'one particular sensory system is utilised' and that for a broader and balanced art and design curriculum the experiential learning of volume and mass in 3D is 'vital'. While Ash's attention is focused on sculpture, I would suggest his quotation of Golomb also applies to film photography: 'tactile contact with the material fosters a more intimate involvement in the making process ...' (Ash in Addison \&
Burgess 2000, 212). To restrict students to 2D, to a virtual screen based photography in this case, is to 'deny' the student 'access to the full range of meaning' (Ash in Addison \& Burgess 2000, 213).

The alchemy or 'magic' that is particular to photography is perhaps only matched by ceramics within art and design. It has a transformative power, not just to the image but also to the student's learning and development (see Table 7). With regard to Benjamin's (1992) theory of an image's 'aura', there would appear to be a similar reverence of the chemical photographic print. As one student said:

And I love having the opportunity to create a print in the trays with chemicals and you can see every little thing you are doing, it's amazing, like when you put the image in the developer and you can see the image coming out, that's amazing. (Female AS Pref Film)

There is a special quality to printing by hand that is not present when clicking 'print' on a computer, the learning is deeper and more significant to the student:

It's interesting to learn how it was done traditionally in the darkroom, and I think it's almost like you feel like you're doing it yourself. (Female AS No Pref)

They feel more in control with a tangible medium. The mechanical aspect allows for precise and fine changes. This suits one particular student with OCD (Obsessive Compulsive Disorder) who feels he can have greater control by measuring millilitres of liquid and seconds of time. With exact changes in exposure and changes of filters the students are learning fine distinctions of differentiation in image quality. Image differentiation is a key principle in art education (Eisner 2002).

The hand-and-eye coordination required to manipulate a mouse (because pen and tablet are rarely seen outside industry) and a cursor on screen is very different to that required in a darkroom. The questionnaire confirms the 
Table 8 : Do students spend their free time playing games and making art on computers?

207

I spend my free time playing computer games and/or creating my own artwork on my computer.
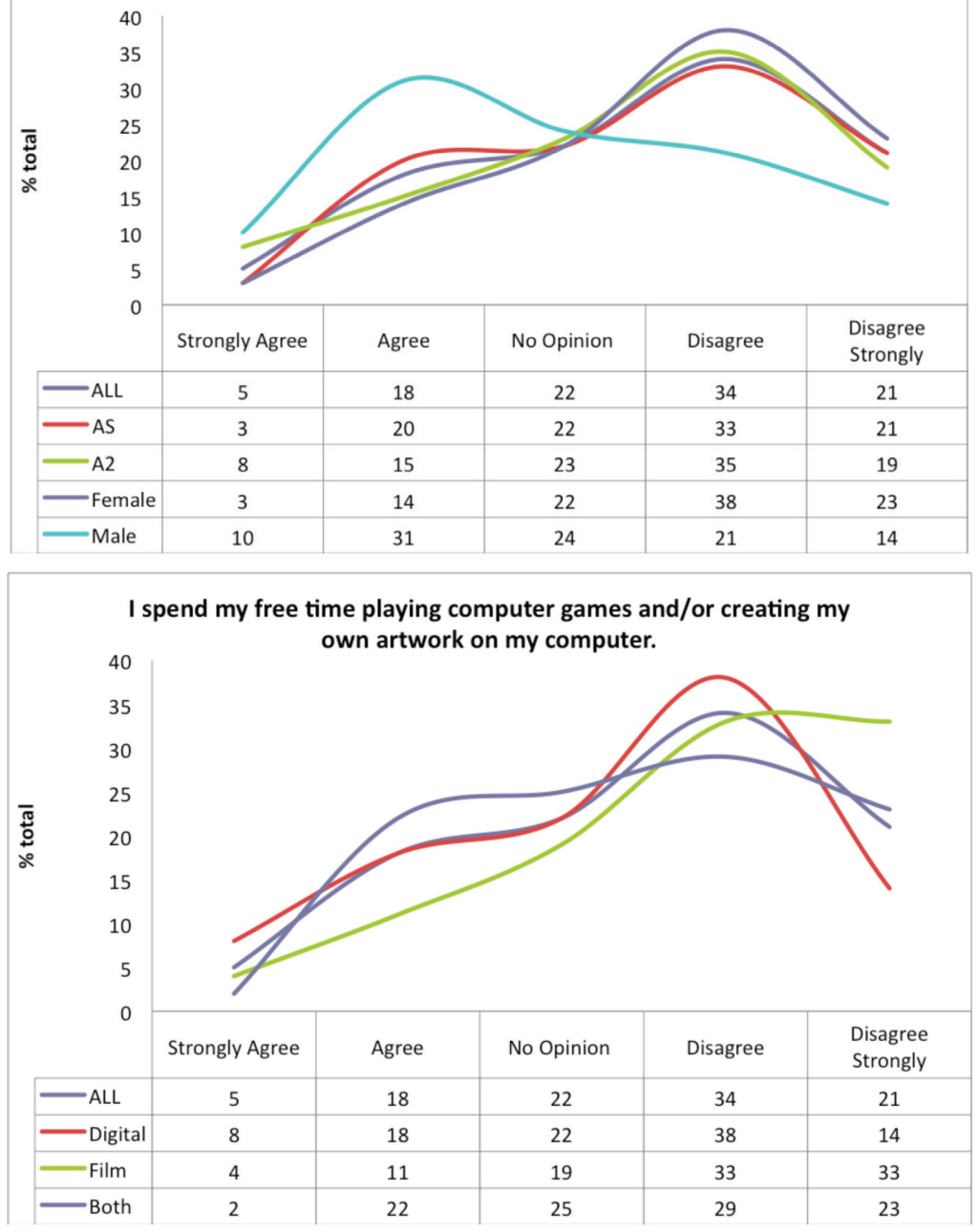

view that more boys are engaged in gaming and computer use at home than girls (see Table 8). Whether or not that makes their digital manipulation skills better developed is unproven. Using a computer to create digital images has not inhibited the uptake of photography by girls in the slightest as they now outnumber boys 3 to 1 (see Table 3). But the careful precision required to draw around elements on screen takes a great deal of concentration and coordination. This is both a technical and creative skill because the line can be drawn in various ways and the choice is

a creative one. The only comparable fine handand-eye control used in the darkroom is a technical skill when a negative is focused on the enlarger.

Photoshop works on the principle of virtual layers, which can change in transparency, effects and indeed in limitless variations. Some students can find layers hard to visualise and comprehend; they need to have something more tangible to be creative with. A negative held in the hand and overlapped with another negative before placing it in the enlarger does require dexterity and sharp
Opposite page:

Figure 5

AS student digital photograph 
Table 9 : Is there a difference between a film and a digital image?

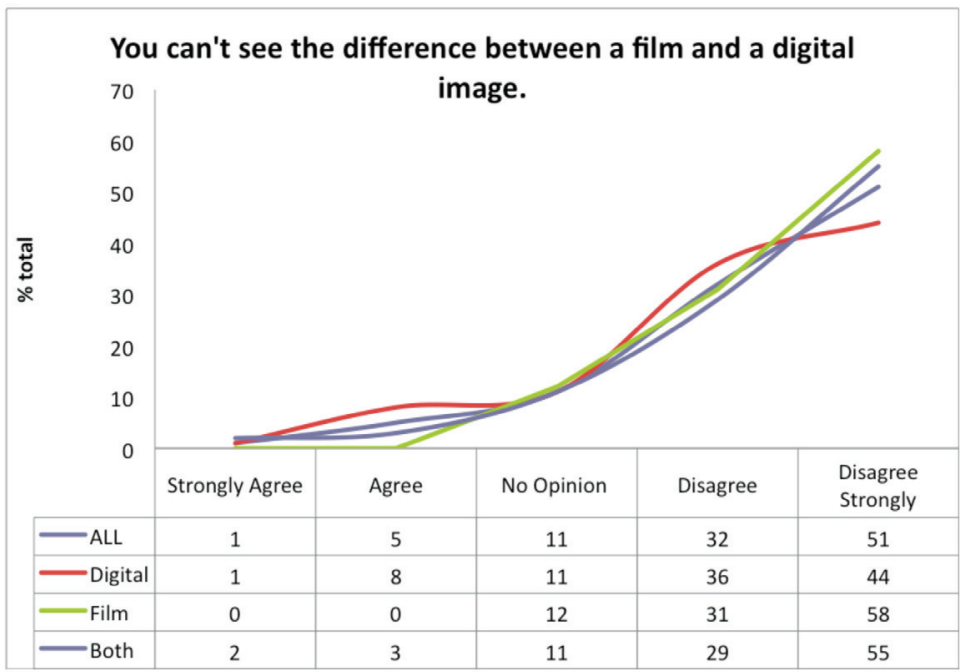

eyesight in the red light of the darkroom (see Figure 6). The hand-and-eye coordination used to create shapes of light or shadow with clasped hands or bits of card on wire to dodge and burn is also a skill, but a creative one. The hands move between the lens of the enlarger and the photographic paper in a shadow play that lasts for a matter of seconds. It is a looser and more fluid movement than tracing a cursor with a mouse, which can take minutes and place stress on the muscles of the hand.

It appears that within photography these specialising groups have much in common. Irrespective of the students' preference for different technologies, it appears that all the students learnt through an experiential method, but this should not be surprising given the practical nature of using and controlling a camera and the reflexive nature of photography. 'Experiential learning is recognised as a reflexive activity, where action and reflection are coexistent, both interdependent and interactive' (Addison \& Burgess 2000, 31).

\section{Conclusion}

Attacked by light, by humidity, itfades, weakens, vanishes; there is nothing left to do but throw it away. (Barthes 2000, 93)
I like it because you can record a moment in a piece of paper and I think that is amazing, when photography is like stopping time, and I love that. (Female AS Pref Film)

Photography is, by its very nature, of the moment, but it is a subject that teenagers feel instinctively is their mode of communication. The students in this study have at times eloquently put forward their own arguments for maintaining analogue film photography in the art and design curriculum. The unique opportunities that film has compared to digital are now clearer to see. Whatever their learning style or preference, students show a compelling desire to learn experientially, and film's tangible, real and tactile quality gives a concrete knowledge that follows on to the virtual screen-based instruction of digital photography. I would argue that for those learning photography film is as important as clay, plaster and paint for those in art and design. Addison warns those who are flattered by the gaze of the lens:

With a mind to futures, it is only by working with concrete materials that students can harness creative processes so as to affect and transform the physical environment and landscape of images and their cultural uses. (Addison et al. 2010, 56) 


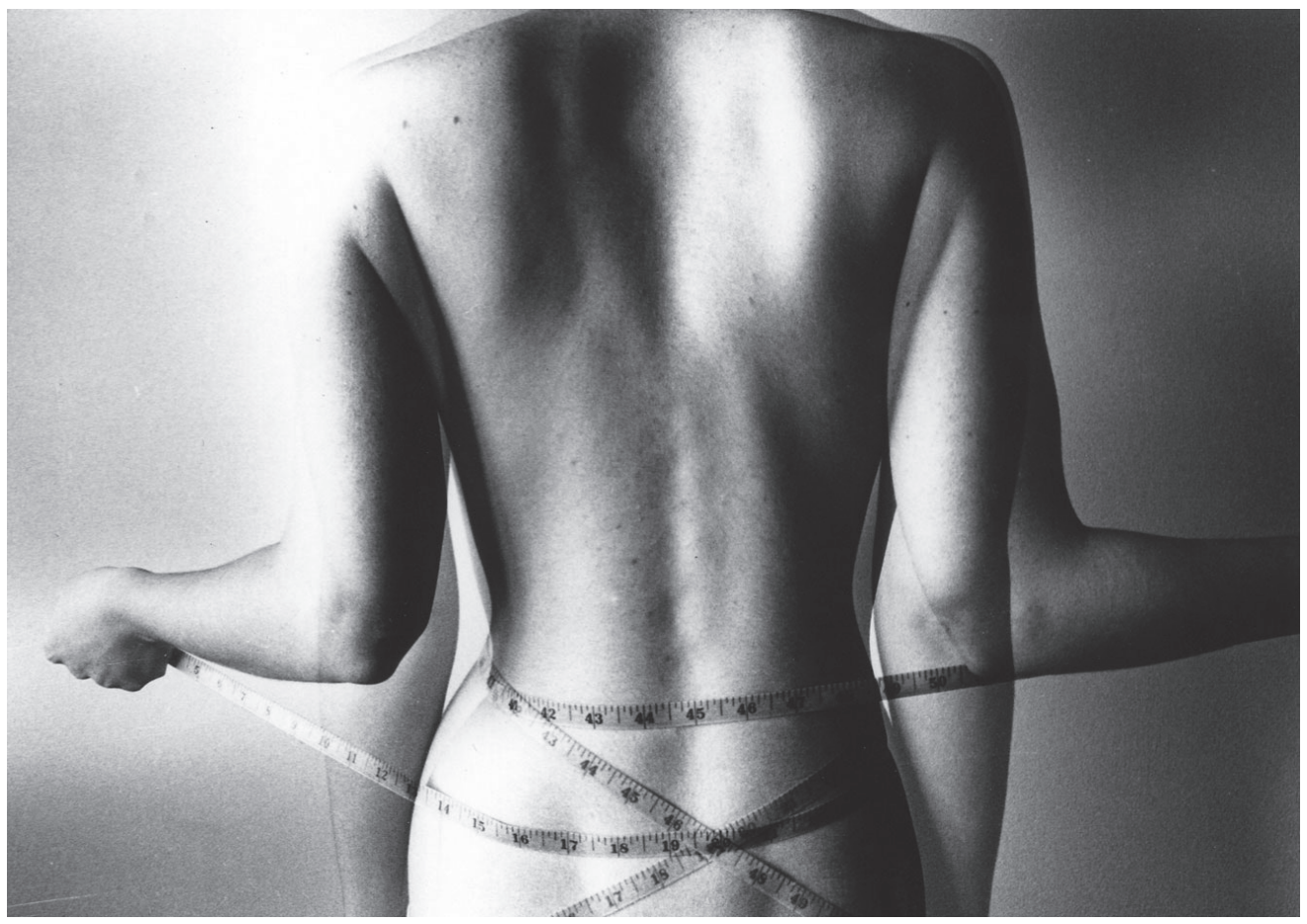

209

lain Macdonald

The students in this study appreciated having a choice, they want the best of both worlds photography should be a hybrid activity with the permanence and future proofing of a negative but the limitless opportunity of digital postproduction. They are not alone: photography undergraduate students at the university where I now lecture also work in this way. 'For the foreseeable future analog and digital should coexist ... complementing and challenging each other's biases and possibilities' (Ritchin 2009, 183). Steers $(2009,127)$ also reminds us that 'orthodoxy is the antithesis of creativity'.

The popularity of photography should ensure that there remains a cult of analogue and film. It will continue to attract the inquisitive and the enthusiast. While the rest digitalise every angle and moment, they will select, edit and compose with purpose and intuition carefully measuring the remaining light until they come to the end of their roll of film. When paper and digital files are lost, all we are left with is the memory of the experience of photographing the moment, 'Today everything exists to end in a photograph' (Sontag 1979, 24).

lain Macdonald is a lecturer in graphic design at Edinburgh Napier University. He has recently completed an MA Art \& Design in Education at the Institute of Education following a PGCE Art \& Design. He has taught A Level Photography at The Henley College, Foundation Diploma at Ravensbourne and degree courses at Ravensbourne and London College of Communication. He has over 20 years' industry experience as a television graphic designer at BBC Television and is a freelance film director and photographer. Contact address: School of Creative Industries, Edinburgh Napier University, Colinton Road, Edinburgh EH10 5DT, UK. Email: i. macdonald@napier.ac.uk
This page:

Figure 6

AS student film photograph 
210

lain Macdonald

\section{References}

Addison, N. \& Burgess, L. [Eds] (2000) Learning to Teach Artand Design in the Secondary School. London: Routledge

Addison, N., Burgess, L., Steers, J. \& Trowell, J. (2010) Understanding Art Education. London: Routledge

Adobe (2010) Photoshop (online). Available at: www.adobe.com/products/photoshop/ compare (accessed 4 August 2010)

Allen, D. (2003) Visual literacy and a head for heights, in N. Addison \& L. Burgess [Eds] /ssues in Artand Design Teaching. London:

Routledge, pp. 98-106

Ash, A. (2000) Attitudes to making, in N. Addison \& L. Burgess [Eds] Learning to Teach Artand Design in the Secondary School. London: Routledge, pp. 210-19

Ash, A. (2004) Bite the ICT bullet: using the world wide web in art education, in R. Hickman [Ed.] Art Education 11-18: Meaning, Purpose and Directions, 2nd edn. London: Continuum, pp. 89-104

Barthes, R. (2000) Camera Lucida. London: Vintage

Baudrillard, J. (2009) Why Hasn't Everything Already Disappeared? London, New York and Calcutta: Seagull

Bell, J. (1999) Doing your Research Project: A Guide for First-Time Researchers in Education and Socia/ Science. Buckingham and Philadelphia: Open University Press

Benjamin, W. (1992) /lluminations. London: Fontana Press

Bourdieu, P. (1990) Photography A MiddleBrow Art. Oxford: Polity Press

Buckingham, D. \& Sefton-Green, J. (1994) Cultural Studies Goes to School. London: Taylor and Francis

Cohen, L., Manion, L. \& Morrison, K. (2007) Research Methods in Education, 6th edn. London and New York: Routledge
Davies, T. \& Worrall, P. (2003) Thinking out of the box, in N. Addison and L. Burgess [Eds] Issues in Artand Design Teaching. London: Routledge, pp. 90-7

Downing, D. \& Watson, R. (2004) School Art: What's in It?: Exploring Visual Arts in Secondary Schools. Slough: National Foundation for Educational Research

Eisner, E. (2002) The Arts and the Creation of Mind. New Haven and London: Yale University Press

Erixon, P. (2010) School subject paradigms and teaching practice in lower secondary Swedish schools influenced by ICT and media, Computers and Education, Vol. 54, No. 4, pp.1212-21

Flickr (2009) blog, 12 October (online). Available at: http://blog.flickr.net/ en/2009/10/12/4000000000/ (accessed 2 May 2010)

Freedman, K. (2003) Recent shifts in US art education, in N. Addison and L. Burgess [Eds] Issues in Artand Design Teaching. London: Routledge, pp. 8-18

Gardner, H. (1996) Intelligence: Multiple Perspectives. London: Harcourt College Publishers

Giroux, H. (2009) Teenage sexuality, body politics and the pedagogy of display (online). Available at: www.henryagiroux.com/online articles/teenage _ sexuality.htm (accessed 4 March 2009)

Hardcastle, P. (2004) Digital Cameras in Teaching and Learning. Leicester: NIACE Hickman, R. [Ed.] (2009) Research in Artand Design Education. Bristol: Intellect

Long, S. (2001) Multimedia in the art curriculum: crossing boundaries, Journal of Art \& Design Education, Vol. 20, No. 3, pp. 255-63

Mayer, R. (2003) What causes individual differences in cognitive performance? in $\mathrm{R}$. Sternberg \& E. Grigorenko [Eds] The Psychology 
of Abilities, Competencies, and Expertise. Cambridge: Cambridge University Press, pp. 263-74

Meecham, P. (2000) Art and technology, in N. Addison \& L. Burgess [Eds] Learning to Teach Art and Design in the Secondary School. London: Routledge, pp. 220-6

Newbury, D. (1997) Talking about practice: photography students, photographic culture and professional identities, British Journal of Sociology of Education, Vol. 1, No. 3, pp. 421-34

Newbury, D. (2004) Changing practices: art education and popular visual culture, in R. Hickman [Ed.] Art Education 11-18: Meaning, Purpose and Direction. London: Continuum, pp. 73-88

OFSTED (2009) Drawing Together: Art, Craft and Design in Schools. London: HMSO

Prensky, M. (2001) Digital natives, digital immigrants, On the Horizon, Vol. 9, No. 5, pp. 1-6

Radclyffe-Thomas, N. (2008) White heat or blue screen? Digital technology in art \& design education, International Journal of Art \& Design Education, Vol. 27, No. 2, pp. 158-67

Ritchin, F. (2009)After Photography. London: Norton

Sontag, S. (1979) On Photography. London: Penguin

Steers, J. (2009) Creativity: delusions, realities, opportunities and challenges, International Journal of Art \& Design Education, Vol. 28, No. 2, pp. 126-38

Watson, D. (2001) Pedagogy before technology: re-thinking the relationship between ICT and teaching, Education and Information Technologies, Vol. 6, No. 4, pp. 251-66
Wells, L. [Ed.] (2004) Photography: A Critical Introduction, 3rd edn. London: Routledge

211

Williams, R. (1981) Culture. London: Fontana Press

Wood, J. (2004) Open minds and a sense of adventure: how teachers of art \& design approach technology, International Journal of Art \& Design Education, Vol. 23, No. 2, pp. 179-91 